\title{
Matemática financeira no ensino médio técnico: análise de erros apresentados por alunos do terceiro ano
}

\author{
Maurício de Moraes Fontes (i)
}

\author{
Dineusa Jesus dos Santos Fontes(D)
}

\section{Resumo}

A Matemática Financeira é um tópico da Matemática que merece muita atenção, pois está diretamente ligado ao cotidiano dos cidadãos. O propósito deste estudo foi analisar os erros e dificuldades cometidos pelos alunos do terceiro ano do ensino médio técnico em questões de Matemática Financeira básica, em Belém do Pará, em 2017. A metodologia aplicada foi a Qualitativa, com estudo descritivo. A amostra foi não probabilística, com dezessete estudantes de uma turma do terceiro ano do ensino médio dessa escola. Para coletar os dados utilizou-se uma prova de dez questões discursivas sobre os fundamentos de Matemática Financeira. Os resultados apresentados nesse estudo parecem demonstrar que os tópicos de variação percentual e juros compostos foram os de maior dificuldade apresentados por eles, e os erros predominantes foram devido às dificuldades de linguagem e a um deficiente aprendizado de fatos, habilidades e conhecimentos prévios.

Palavras-chave: Análise de erros. Matemática Financeira. Alunos. Ensino Médio.

\begin{abstract}
Financial Mathematics is a Mathematical topic that deserves much attention, as it is directly linked to the daily lives of citizens. The purpose of this study is to analyze the errors and difficulties made by the students of the third year of technical high school in matters of Basic Financial Mathematics in Belém do Pará in 2017. The applied methodology is the Qualitative with Descriptive study. The sample is non-probabilistic with seventeen students from a third year high school class. To collect the data, we used a test of ten discursive questions about the fundamentals of Financial Mathematics. The results presented in this study seem to demonstrate that the topics of percentage variation and compound interest were the questions with the most difficulties presented by them and the predominant errors were due to language difficulties and poor learning of facts, skills and previous knowledge.
\end{abstract}

Keywords: Error analysis. Financial Mathematics. Students. High school. 


\section{Introdução}

A Matemática Financeira é um tópico da Matemática que merece muita atenção por estar diretamente ligada ao cotidiano dos cidadãos, dos estudantes de qualquer nível de escolaridade e das pessoas que não fazem parte deste contexto.

[6, p.71] afirma "em nosso dia a dia é comum observarmos expressões como estas: Desconto de até $30 \%$ na grande liquidação de verão; Os jovens perfazem um total de $50 \%$ da população brasileira; A inflação registrada em dezembro foi de 1,93\%; O rendimento da caderneta de poupança foi de 1,99\% em dezembro."

Todas essas expressões envolvem uma razão especial chamada porcentagem.

A falta desse conhecimento na vida das pessoas traz consequências significativas para as famílias, haja vista que desequilíbrio financeiro, falta de investimento em educação, falta de um plano de saúde, nome incluso no Serasa, são situações administráveis quando o usuário ou cidadão tem esclarecimento.

Essa má-formação, que implica os resultados obtidos, expõe a falta de conhecimentos básicos de Matemática Financeira, demonstrada, inclusive, pelos meios de comunicação que expõem um índice alarmante de mais de treze milhões de desempregados na sociedade brasileira ${ }^{1}$ atualmente. Tal lacuna deixada nas pessoas pode vir da família, que deveriam ter a função de orientar os filhos para aprender a administrar o dinheiro. Por outro lado, também pode vir da escola, já que os professores deveriam possibilitar ao alunos numa boa formação sobre finanças, mas o que observamos na prática é que muitos estudantes demonstram o desconhecimento em Matemática Financeira, apresentando muitos erros conceituais fundamentais sobre noções básicas de finanças.

Em [10, p. 116], temos que "A Matemática Financeira é um assunto da Matemática muito importante para que os estudantes possam compreender as relações envolvendo dinheiro no seu dia a dia. Em todos os momentos, os discentes estão se envolvendo com porcentagens, juros, taxas, entre outros elementos que compõem os conceitos básicos de Matemática Financeira".

Pelo apresentado acima, esse trabalho teve como propósito analisar as dificuldades e os erros cometidos pelos alunos do terceiro ano do ensino médio técnico em questões de Matemática Financeira básica, em Belém do Pará, 2017.

\section{Marco Teórico}

\subsection{Ensino de Matemática Financeira}

Para [1, p.1]: "a Matemática Financeira trata, em essência, do estudo do valor do dinheiro ao longo do tempo. O seu objetivo básico é o de efetuar análises e comparações dos vários fluxos de entrada e saída de dinheiro de caixa verificados em diferentes momentos". Duzentos reais hoje não terão o mesmo valor que duzentos reais daqui a um ano; o poder de compra já não é mais o mesmo.

Essas entradas e saídas do dinheiro podem ser entendidas tanto numa empresa quanto no seio familiar. Administrar o que se ganha é uma tarefa que precisa de conhecimentos básicos sobre esse assunto. Nesse sentido, para [3, p.1]: "A Matemática Financeira é um segmento da Matemática

\footnotetext{
${ }^{1}$ Dados disponível em:

https://www.brasildefato.com.br/2019/05/16/quase-40-dos-desempregados-esta-ha-mais-de-um-ano-sem-trabalho-aponta-ibge/. Acesso em 17 jul. 2019.
} 
que reúne uma série de conceitos os quais contribuem para que os indivíduos possam exercer sua cidadania em um mundo capitalista".

\subsection{O Erro no Ensino de Matemática}

Dentro do Ensino de Matemática, o erro aparece permanentemente nas produções dos alunos mostrando as dificuldades apresentadas por eles no processo de ensino e aprendizagem.

Segundo [9, p.1] "o erro deve ser considerado como a presença de um esquema cognitivo do aluno de forma inadequada e não somente a consequência de uma falta específica de conhecimento ou uma distração".

Para analisar os erros provenientes das respostas dos discentes, usaremos a classificação de Radatz (1979), citado por [14, pp. 88-90], que estabelece cinco categorias gerais:

1. Erros devido a dificuldades de linguagem (E1): Determina que o aprendizado dos conceitos, símbolos e vocabulário matemático é para muitos alunos um problema semelhante ao aprendizado de uma língua estrangeira. Uma falta de compreensão semântica dos textos matemáticos é fonte de erros; por isso, a resolução de problemas verbais está especialmente aberta a erros de tradução desde um esquema semântico na linguagem natural a um esquema mais formal na linguagem matemática.

2. Erros devido a dificuldades para obter informação espacial (E2): Ainda que se trate de um campo de estudo cujo desenvolvimento se está iniciando, é certo que as diferenças individuais na capacidade para pensar mediante imagens espaciais ou visuais é uma fonte de dificuldades para muitos jovens e crianças na realização de tarefas matemáticas. Algumas representações icônicas de situações matemáticas podem supor dificuldades no processamento da informação; a análise e síntese perceptivas implicam uma demanda considerável para alguns alunos, apresentando dificuldades e produzindo erros.

3. Erros devido a um aprendizado deficiente de fatos, habilidades e conceitos prévios (E3): Neste tipo de err incluem-se todas as diferenças de conhecimento sobre conteúdos procedimentais específicos para a realização de uma tarefa matemática. Essas deficiências incluem a ignorância dos algoritmos, conhecimentos inadequados de fatos básicos, procedimentos incorretos na aplicação de técnicas e domínio insuficiente de símbolos e conceitos matemáticos.

4. Erros devidos a associações incorretas ou a rigidez do pensamento (E4): A experiência sobre problemas similares anteriores pode produzir uma rigidez no modo habitual de pensamento e uma falta de flexibilidade para codificar e decodificar nova informação. Nesses casos os alunos desenvolvem operações cognitivas, que continuam empregando ainda quando as condições fundamentais da tarefa matemática em questão tenham se modificado. Persistem na mente alguns aspectos do conteúdo ou do processo de solução, inibindo o processamento de nova informação. Dentro dessa classe de erros encontram-se os seguintes:

Erros por perseveração, em que predominam elementos singulares de uma tarefa ou problema.

Erros de associação, que incluem interações incorretas entre elementos singulares.

Erros de interferência, em que operações ou conceitos diferentes interferem com outros.

Erros de assimilação, em que uma audição incorreta produz falhas na leitura ou escritura. 
Erros de transferência negativa a partir de tarefas prévias, em que pode identificar o efeito de uma impressão errada obtida de um conjunto de exercícios ou problemas verbais.

5. Erros devido à aplicação de regras ou estratégias irrelevantes (E5): Esses tipos de erros surgem com frequência por aplicar com êxito regras ou estratégias similares em áreas de conteúdos diferentes.

Usaremos essas categorias propostas por Radatz citadas acima para analisar os erros apresentados pelos discentes nesta pesquisa, levando em consideração a orientação dada por [7, p.2] que diz "que se entenda como erro, na resolução de uma questão, o que não corresponde à produção esperada de um aluno (ou professor) que já deve ter tido contato com os conteúdos apresentados na referida questão ou com estratégias de resolução de problemas em Matemática".

\section{Marco Metodológico}

A metodologia aplicada no presente trabalho foi a Qualitativa, pois "a investigação qualitativa é a sondagem com que os investigadores recolhem os dados em situações reais por interação com pessoas selecionadas em seu próprio entorno" [12, p.400].

A amostra foi intencional, pois, ao contrário da determinação de probabilidade, consiste em "selecionar casos com abundante informação para estudos detalhados" [12]

Utilizamos uma prova escrita com dez questões sobre conhecimentos básicos de Matemática Comercial e Financeira, a saber: razão, proporção, regra de três, porcentagem e juros. A prova foi realizada em uma turma do terceiro ano do Ensino Médio em uma escola técnica estadual em Belém do Pará, no ano de 2017.

\section{Análise e Discussão dos Resultados}

Neste estudo, trabalhamos com dezessete estudantes do Ensino Médio Técnico de uma escola pública em Belém do Pará, sendo $41,18 \%$ do sexo masculino e 58,82\% do sexo feminino. Esses discentes serão indicados aqui de D1 a D17.

No dia onze de maio de 2017, antes de iniciarmos o projeto pedagógico "A importância da Matemática Financeira para os alunos do Ensino Médio", fizemos um estudo exploratório com os educandos que estão concluindo o ensino médio. Apresentamos a eles dez questões discursivas retiradas dos livros de [2], [13], [8], [11], [4] e [5].

A primeira questão desse teste teve como objetivo calcular a densidade demográfica de cada uma das regiões de nosso país. No caso em questão, seis estudantes resolveram a questão corretamente e cinco não apresentaram nenhuma resolução para a questão; dois discentes acertaram o cálculo da maioria das regiões pedidas, porém erraram o cálculo de apenas uma delas. A Figura 1 abaixo mostra a resolução de um deles. 
$1 \mathrm{Na}$ tabela, temos a área e a população aproximada das regiōes brasileiras, segundo dados do Anuário Estatístico do Brasil 2000.

\begin{tabular}{|l|c|c|}
\hline Região & Área $\left(\mathbf{k m}^{2}\right)$ & População \\
\hline Norte & $3850000:$ & 12893561 \\
\hline Nordeste & $1555000 \div$ & 47693253 \\
\hline Sudeste & 925000 & 72297351 \\
\hline Sul & 575000 & 25089783 \\
\hline Centro-oeste & $1605000=$ & 11616745 \\
\hline \multicolumn{3}{|c|}{ Fonte: Anuário estatístico do Brasil, Rio de Janeiro: } \\
IBGE, 2002.
\end{tabular}

a) Qual era a densidade demográfica de cada região?

Noote $=3,3,48$

Nordest : 30,67

Sudeste 78,15

sull 93,63

contro 7,23

b) Qual era a região de maior densidade

demográfica? Sucleste.

c) Qual era a região de menor densidade demográfica?

$$
\text { contion sonto }
$$

Figura 1: Protocolo de D10. Fonte: Pesquisa de Campo.

A aluna D10 errou o cálculo da região Norte e como consequência errou a pergunta feita na letra c acima.

Ainda sobre a primeira questão, quatro estudantes erraram sua resolução; por exemplo, a aluna D1, cujo protocolo está mostrado na Figura ?? abaixo.

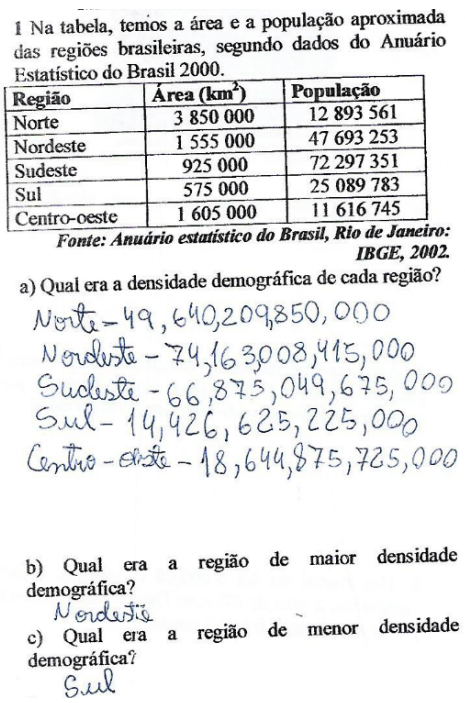

Figura 2: Protocolo de D1. Fonte: Pesquisa de Campo.

Observamos pela Figura 2 acima, que a aluna, em vez de dividir o número de habitantes das regiões 
pelas respectivas áreas correspondentes, multiplicou esses valores. Ela demonstra não ter entendido o conceito de densidade demográfica, que significa a razão do número de habitantes de determinada região pela sua área correspondente. Temos que [10, p.121], em sua pesquisa com alunos do ensino médio regular, encontrou resultado parecido com esse em seu estudo, quando afirma: "Dos outros vinte e cinco por cento, o estudante multiplicou a área pela população correspondente, (...) e no final ainda errou o cálculo dessa multiplicação". O tipo de erro predominante nesse caso foi conceitual, o que, de acordo com a categorização de Radatz (1979) citado por [14], é o erro (E3).

$\mathrm{Na}$ segunda questão de nosso teste, cujo propósito foi de calcular razão direta numa situação contextualizada, somente dois estudantes resolveram corretamente a questão pedida, e sete não apresentaram nenhuma resolução. Três resolveram em parte a questão; entre eles vamos registrar a resolução de um desses estudantes.

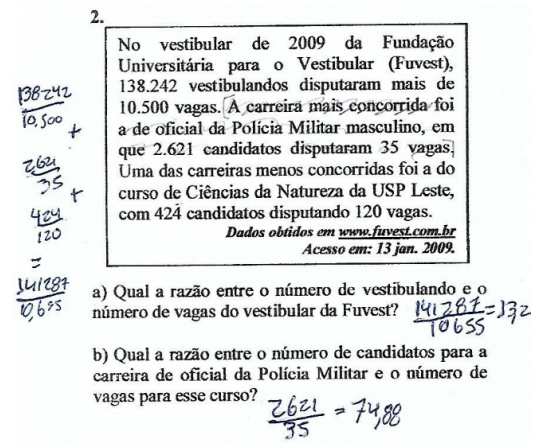

Figura 3: Protocolo de D3. Fonte: Pesquisa de Campo.

Na Figura 3 acima, letra a, o aluno parece ter somado o número total de candidatos $(138242+$ $2621+424=141287)$ e o total de vagas $(10500+35+120=10655)$ e depois dividiu esses valores, apresentando, assim, o erro (E1). Já o item b, ele acertou. Contudo, cinco erraram a resolução dessa questão. Entre esses que erraram a questão, a aluna D17 apresentou erro (E1), isto é, erro devido à dificuldade de linguagem, como mostra a Figura 4 abaixo.

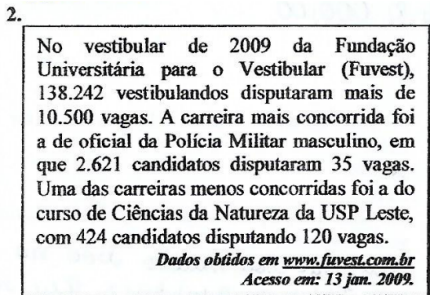

a) Qual a razão entre o número de vestibulando e o número de vagas do vestibular da Fuvest?

É que os alis pros proferivan $\theta$ curso de PM

b) Qual a razão entre o número de candidatos para a carreira de oficial da Polícia Militar e o número de vagas para esse curso?

A rialincio no país. E o ratirio agrada muito das que queren

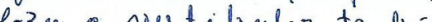

Figura 4: Protocolo de D17. Fonte: Pesquisa de Campo. 
A discente D17 demonstra não ter interpretado o comando da questão corretamente, ou seja, era para calcular a razão entre os elementos pedidos.

Os demais alunos, ao resolverem a segunda questão, apresentaram erro conceitual, erro (E3), isto é, erro devido a um aprendizado deficiente de fatos, habilidades e conceitos prévios, como mostra a resolução da estudante D6.

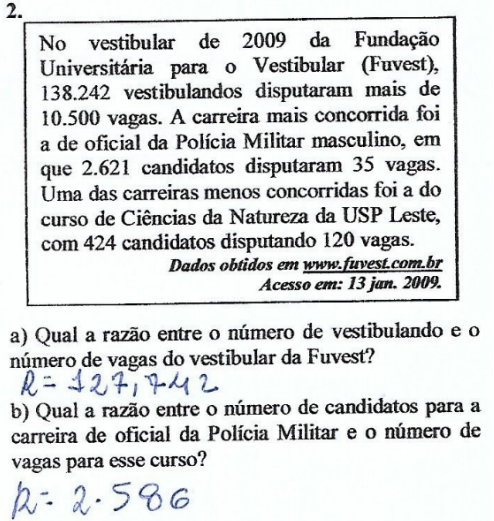

Figura 5: Protocolo de D6. Fonte: Pesquisa de Campo.

A Figura 5 acima mostra que a aluna apresentou um erro conceitual, pois em vez de dividir o número de vestibulandos pelo número de vagas, subtraiu esses valores.

Na terceira questão de nosso teste, cujo propósito foi calcular regra de três simples; oito alunos resolveram a questão corretamente, dois não apresentaram nenhuma resolução para a situação-problema e cinco educandos resolveram a questão parcialmente. A Figura 6 abaixo expõe a resolução de um deles.

\begin{tabular}{|c|c|c|}
\hline \multicolumn{3}{|c|}{ Valor energético por porção de alguns alimentos } \\
\hline Alimento & Porçäo & kcal \\
\hline Muçarela & $30 \mathrm{~g}$ & 80 \\
\hline Palmito & $100 \mathrm{~g}$ & 5 \\
\hline Panetone & $80 \mathrm{~g}$ & 150 \\
\hline Sorvete & $45 \mathrm{~g}$ & 130 \\
\hline \multicolumn{3}{|c|}{$\begin{array}{l}\text { Fonte de pesquisas: Anvise. Disponivel e } \\
\text { www.anvisa.gov.br/alimentos/rotulos/manual rotulget }\end{array}$} \\
\hline \multicolumn{3}{|c|}{$\begin{array}{l}\text { pdf. Acesso em: } 11 \text { abr. } 2015 \\
\text { a) Quantas quilocalorias têm } 100 \mathrm{~g} \text { de palmito? } \\
\qquad 5 \\
\text { b) Aproximadamente, quantas quilocalorias têm } 10 \\
\text { g de Muçarela? }\end{array}$} \\
\hline
\end{tabular}

Figura 6: Protocolo de D13. Fonte: Pesquisa de Campo.

O aluno acertou a resposta da letra a; no entanto, errou a resolução da letra b, como mostra a Figura 6 acima. Ele não conseguiu resolver uma regra de três simples para esse item, apresentando, 
assim, o erro (E3).

E dois estudantes resolveram erradamente a questão. Nesta situação, vamos mostrar a resolução apresentada por D2, na Figura 7.

\begin{tabular}{|c|c|c|}
\hline \multicolumn{3}{|c|}{ 3. Observe o valor energético de alguns alimentos. } \\
\hline \multicolumn{3}{|c|}{ Valor energético por porção de alguns alimentos } \\
\hline Alimento & Porção & kcal \\
\hline Muçarela & $30 \mathrm{~g}$ & 80 \\
\hline Palmito & $100 \mathrm{~g}$ & 5 \\
\hline Panetone & $80 \mathrm{~g}$ & 150 \\
\hline Sorvete & $45 \mathrm{~g}$ & 130 \\
\hline \multicolumn{3}{|c|}{$\begin{array}{l}\text { Fonte de pesquisa: Anvisa. Disponivel en } \\
\text { I }\end{array}$} \\
\hline \multicolumn{3}{|c|}{$\begin{array}{l}\text { pdf. Acesso em: } 11 \text { abr. } 2015 \\
\text { a) Quantas quilocalorias têm } 100 \mathrm{~g} \text { de palmito? } \\
\text { PALM. } 5 \div 100=0,05 \\
\text { b) Aproximadamente, quantas quilocalorias têm } 100 \\
\text { g de Mucarela? }\end{array}$} \\
\hline$M U C_{5}=$ & $2 1 \longdiv { 6 }$ & \\
\hline
\end{tabular}

Figura 7: Protocolo de D2. Fonte: Pesquisa de Campo.

Essa aluna apresentou dificuldades na leitura da tabela acima, visto que não prestou atenção que a tabela já fornece a resposta para a letra a, apresentando assim erro (E1), e, para a letra b, bastaria fazer uma regra de três simples ou dando continuidade ao que parece que estava pensando, bastava multiplicar o resultado apresentado por cem.

Tal questão também poderia ter sido resolvida por meio do cálculo proporcional, já que "o conceito de proporção tem uma importância muito grande, não apenas em Matemática, como também no cotidiano" [6, p.15].

A quarta questão teve como objetivo calcular regra de três composta. Somente dois alunos resolveram a questão corretamente, treze deixaram em branco e dois estudantes resolveram erradamente, dentre eles, vamos registrar a resolução de D3, em que o aluno tentou resolver a questão por meio de duas regras de três simples, como mostra a Figura 8 abaixo, encontrando dois valores para a quantidade de dias procurada. Dessa forma, o aluno demostrou não saber como resolver uma regra de três composta. E como ele não inverteu a grandeza número de homens, apresentou o erro (E3).

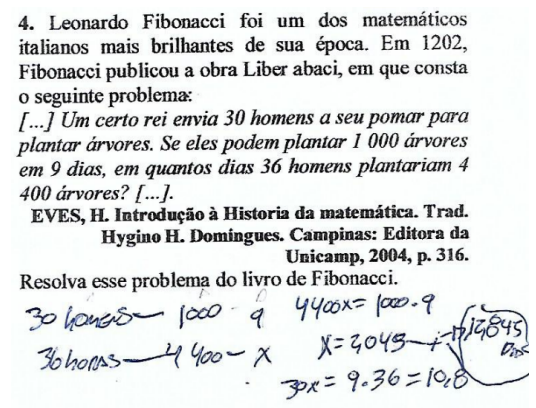

Figura 8: Protocolo de D3. Fonte: Pesquisa de Campo. 
Ao analisar as respostas dos alunos nessa pesquisa, bem como da experiência de sala de aula, constata-se que um dos problemas enfrentados por alguns estudantes quando chegam no ensino médio é que para eles todas as grandezas parecem que são diretamente proporcionais. Eles não analisam quando elas são diretamente ou inversamente proporcionais para depois armarem a proporção necessária para resolver o que foi pedido.

Na quinta questão de nosso estudo, o objetivo proposto foi calcular a variação percentual em um determinado período de tempo. Quinze estudantes deixaram a questão em branco, e dois alunos a resolveram erradamente. Entre eles, apresentamos, na Figura 9 abaixo, o protocolo de D10.

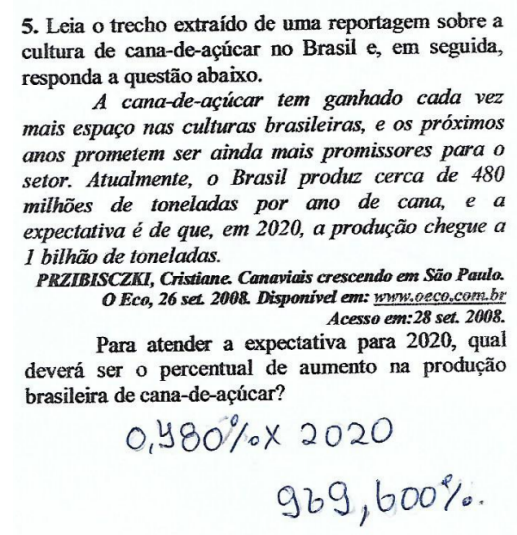

Figura 9: Protocolo de D10. Fonte: Pesquisa de Campo.

Observamos que a aluna parece não ter compreendido o enunciado do problema, porque tudo indica que ela dividiu os 480 por 1000 e depois multiplicou pelo ano pedido de projeção da safra de cana-de-açúcar. Aqui percebemos um erro tipo (E1) por não ter interpretado corretamente o enunciado do problema

A sexta questão de nosso estudo teve como objetivo interpretar e resolver questões apresentadas em uma tabela. Dois discentes resolveram a questão corretamente e quatro deixaram a questão em branco. Todos os demais educandos resolveram a questão parcialmente, acertando o item a dessa questão, que era para identificar a resposta entre os dados da tabela. Desses, quatro deixaram em branco os itens b e c, quatro erraram esses itens, um errou o item c e dois apresentaram respostas que não condizem com o enunciado. Dentre os que erraram, os estudantes D10 e D14 apresentaram erro devido à dificuldade de linguagem (E1), como mostra o protocolo de D10, na Figura 10. 


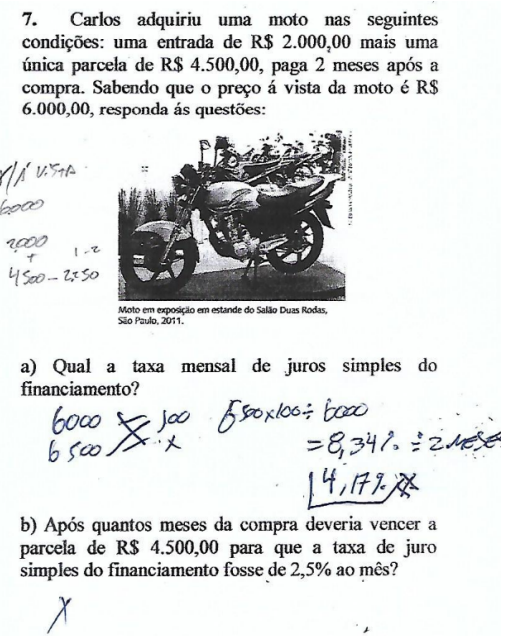

Figura 11: Protocolo de D3. Fonte: Pesquisa de Campo.

Quanto ao item b, este discente D3 não conseguiu desenvolver a atividade proposta para o cálculo do tempo pedido.

Já a estudante D4 parece que pensou em utilizar a fórmula do cálculo de juros simples, como mostra a Figura 12, porém utilizou os valores equivocados em sua resolução. Ela apresentou, assim, o erro (E1).

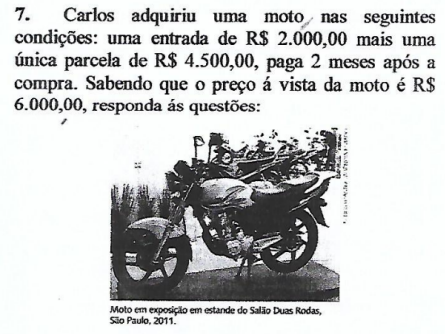

a) Qual a taxa mensal de juros simples do financiamento?

$$
\frac{2.000 \cdot 4.500 .60}{100}=5.4 \%
$$

b) Após quantos meses da compra deveria vencer a parcela de $\mathrm{R} \$ 4.500,00$ para que a taxa de juro simples do financiamento fosse de $2,5 \%$ ao mês?

Figura 12: Protocolo de D4. Fonte: Pesquisa de Campo. 
Observe que ela utiliza o tempo em dias e o problema pede a taxa mensal. Para [1, p.2]: "nas fórmulas de Matemática Financeira, tanto o prazo de operações como a taxa de juros devem necessariamente estar expressos na mesma unidade de tempo".

Quanto ao item b, a aluna D4 não conseguiu desenvolver a resolução, como mostra a Figura 12 acima.

A aluna D6, Figura 13, somou o valor à vista da moto com o percentual pedido no texto (item b), isto é, $6.000+2,5 \%=6.150$. Isso demonstra o erro (E3) na classificação de Radazt (1979) apud [14].

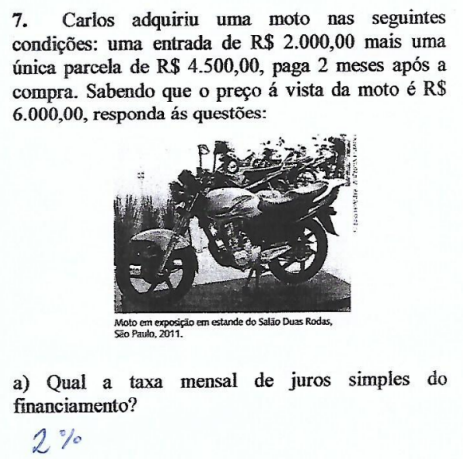

b) Após quantos meses da compra deveria vencer a parcela de $R \$ 4.500,00$ para que a taxa de juro simples do financiamento fosse de $2,5 \%$ ao mês?$$
6000+2,3 \%=6.150
$$

Figura 13: Protocolo de D6. Fonte: Pesquisa de Campo.

Essa falta de conhecimento prévio tem se tornado um problema para os estudantes se desenvolverem em finanças pessoais, já que, para [11, p.8]: "O conhecimento de operações financeiras simples, como cálculo de empréstimos, financiamentos, descontos, taxas de juros e rendimentos de investimentos, é de grande importância para o exercício pleno da cidadania”.

A oitava situação-problema apresentada teve como objetivo calcular o montante de uma aplicação financeira no regime de capitalização composta. Treze alunos não apresentaram nenhuma resolução para a questão e quatro discentes (D3, D4, D6 e D12) resolveram erradamente a questão. O discente D3 errou a resolução da questão, pois tentou resolvê-la por meio de uma regra de três simples, D6 somou o capital ao percentual e o resultado multiplicou pelo tempo; e os estudantes D4 e D12 tentaram resolver essa questão como se fosse uma situação-problema de juros simples. Abaixo, na Figura 14, vamos registrar essa situação com a resolução de um desses educandos. 


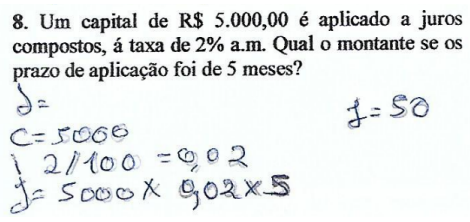

Figura 14: Protocolo de D12. Fonte: Pesquisa de Campo.

O cálculo de Juros compostos tem se mostrado muito difícil para os discentes na última etapa da educação básica. As dificuldades encontradas nesse estudo também foram mencionadas por [10, p.128] que registrou: "e a questão com mais alunos sem nenhuma resolução foi a questão número oito, que trata de juros compostos com vinte provas sem nenhuma resolução". E o fato de tentar resolver as questões de juros compostos com as fórmulas de juros simples também foi mencionado pelo autor acima, nesse mesmo estudo. O tipo de erro apresentado aqui foi o (E5).

A penúltima questão perguntou se os discentes encontraram dificuldades nessas situações-problema propostas a eles, e $94,12 \%$ disseram que sim.

As principais dificuldades mencionadas por eles estão registradas na Tabela 1 abaixo.

\begin{tabular}{|c|c|}
\hline Dificuldades & Discentes \\
\hline \hline Todas & D7, D14, D15 e D16 \\
\hline Porcentagem e Juros & D2, D6 e D10 \\
\hline Interpretação & D8 \\
\hline Juros & D1 \\
\hline Regra de três e Porcentagem & D5 \\
\hline Lembrar o que foi estudado & D4, D9 e D13 \\
\hline Falta de uma calculadora & D11 \\
\hline Não sou boa em matemática & D17 \\
\hline Porcentagem & D12 \\
\hline Não tem dificuldades & D3 \\
\hline
\end{tabular}

Tabela 1: Dificuldades apresentadas pelos alunos nesse teste.

A Tabela 1 acima demonstra as angústias desses educandos. O tópico de porcentagem é o que mais foi mencionado por eles, seguido de juros. Esse fato é preocupante, levando em consideração que a porcentagem é um tema de fundamental importância para a formação dos cidadãos, já que "praticamente todos os dias, ao abrir jornais ou revistas, ouvir rádio, assistir a debates ou à televisão, observamos expressões matemáticas relacionadas à porcentagem.” [13, p. 236].

Apenas um aluno afirmou não ter dificuldade nesse teste, e um estudante mencionou a falta de uma calculadora para ajudar na resolução dessas questões propostas, entretanto, foi permitido o uso da máquina de calcular.

\section{Considerações Finais}

Este trabalho teve como propósito analisar os erros e dificuldades cometidos pelos alunos do terceiro ano do ensino médio técnico em questões de Matemática Financeira básica, em Belém do Pará, 
em 2017.

Nenhum educando acertou as questões referentes a variação percentual e juros compostos. O maior índice de questões sem nenhuma resolução foi no tópico de variação percentual, com 88,23\% dos discentes não apresentando nenhuma resolução para a situação-problema apresentada; e logo depois vieram os problemas de juros simples e de juros compostos, com 76,47\% dos estudantes não apresentando nenhuma resolução para o que foi pedido em cada questão. No tópico de juros simples, somente um aluno acertou a resolução dessa questão. Esses dados reforçam o que foi comentado pelos aprendizes quanto às dificuldades apresentadas por eles, isto é, que a porcentagem e o cálculo de juros foram os maiores obstáculos encontrado para resolver as situações-problema.

O assunto que os alunos mais acertaram foi a regra de três simples, com 47,06\% deles acertando o que foi pedido.

Nas questões de juros compostos, vimos alguns discentes tentando resolvê-las com as fórmulas de juros simples.

Os erros mais frequentes nesse estudo aconteceram devido à dificuldade de linguagem e erros devido a um aprendizado deficiente de fatos, habilidades e conceitos prévios, mas também foram encontrados erros relacionados à aplicação de regras ou estratégias irrelevantes.

Tal situação desses alunos não pode continuar, por isso vamos propor uma sequência de ensino dos tópicos básicos de Matemática comercial e financeira para ser desenvolvida em sala de aula e, posteriormente, aplicar um teste parecido com esse para verificar se haverá uma melhora significativa entre as duas medições.

Finalmente, pensando nos estudantes que estão ingressando no ensino fundamental: que eles possam, efetivamente, ter acesso aos fundamentos da Matemática Financeira, com o propósito de se educar financeiramente para que não se tornem os endividados no futuro. Nesse sentido, defende-se que os tópicos de Matemática Financeira façam parte dos conteúdos de Matemática desde o ensino fundamental.

\section{Referências}

[1] Assaf Neto, A. Matemática Financeira e suas aplicações. 13a ed. São Paulo: Atlas, 2016.

[2] Bianchini, E. Matemática. $7^{\circ}$ ano. $6^{\text {a }}$ ed. São Paulo: Moderna, 2006.

[3] Castelo Branco, A. C. Matemática Financeira Aplicada-Método algébrico, HP - 12C, Microsoft EXCEL. $4^{\mathrm{a}}$ ed. revista e ampliada. São Paulo: Cengage Learning, 2016.

[4] Chavante, E. R. Convergências: Matemática. $7^{\circ}$ ano. São Paulo: Edições SM, 2015.

[5] Chavante, E. R. Convergências: Matemática. 9o ano. São Paulo: Edições SM, 2015.

[6] Crespo, A. A. Matemática Financeira Fácil. 14ª ed. São Paulo: Saraiva, 2009.

[7] Cury, H. N."Análise de Erros". In: "Encontro Nacional de Educação Matemática", 10. Salvador. Anais do X ENEM. Salvador, 2010.

[8] Dante, L. R. Projeto Teláris: Matemática. $7^{\circ}$ ano. $1^{\mathrm{a}}$ ed. São Paulo: Ática, 2012.

[9] Del Puerto, S. M.; Minnaard, C. L. \& Seminara, S. A. "Análisis de los errores: una valiosa fuente de información acerca del aprendizaje de las matemáticas". In: Revista Iberoamericana de Educación. v. 38. $\mathrm{n}^{\mathrm{O}}$ 4. 2006. 
[10] Fontes, M. M. "Matemática Financeira no Ensino Médio: Um estudo exploratório". In: COINSPIRAÇÃO: Revista de professores que ensinam matemática - SBEM/Mato Grosso. V.1, No 2, Julho/Dezembro de 2018.<http://sbemmatogrosso.com.br/publicacoes/>.

[11] Leonardo, F. M. Conexões com a Matemática. $2^{\text {a }}$ ed. Volume 3. São Paulo: Moderna, 2013.

[12] McMillan, J. \& Shumacher, S. Investigación Educativa: una introducción conceptual. $5^{\mathrm{a}}$ ed. Pearson Educación, S. A. Madrid, 2005.

[13] Mori, I. \& Onaga, D. S. Matemática: ideias e desafíos. $7^{\circ}$ ano. $15^{\mathrm{a}}$ ed. São Paulo: Saraiva, 2009.

[14] Rico,"L. Errores en el aprendizaje de las matemáticas". In: Kilpatrick, J.; Rico, L. E\} Gómez, P. (Eds.). Educación Matemática. "una empresa docente". Colombia, 1998.

\section{Maurício de Moraes Fontes Seduc - PA $<$ mauriciofontes@gmail.com>}

Dineusa Jesus dos Santos Fontes Seduc - PA $<$ dineusa@gmail.com>

Recebido: $15 / 08 / 2019$ Publicado: 05/05/2020 